\title{
Novel subpopulations in date palm (Phoenix dactylifera) identified by population-wide organellar genome sequencing
}

Yasmin A. Mohamoud', Lisa S. Mathew', Maria F. Torres ${ }^{2,6}$, Shameem Younuskunju ${ }^{1,3}$, Robert Krueger ${ }^{4}$, Karsten Suhre ${ }^{5}$ and Joel A. Malek ${ }^{1,2^{*}}$ (D)

\begin{abstract}
Background: The date palm is one of the oldest cultivated fruit trees. The tree can withstand high temperatures and low water and the fruit can be stored dry offering nutrition across the year. The first region of cultivation is believed to be near modern day Iraq, however, where and if the date palm was domesticated is still a topic of debate. Recent studies of chloroplast and genomic DNA revealed two major subpopulations of cultivars centered in both the Eastern range of date palm cultivation including Arabian Peninsula, Iraq and parts of South Asia, and the Western range, including North Africa.

Results: To better understand the origins of date palm cultivation we sequenced and analyzed over 200 mitochondrial and chloroplast genomes from a geographically diverse set of date palms. Here we show that, based on mitochondrial and chloroplast genome-wide genotyping data, the most common cultivated date palms contain 4 haplotypes that appear associated with geographical region of cultivar origin.

Conclusions: These data suggest at least 3 and possibly 4 original maternal contributions to the current date palm population and doubles the original number. One new haplotype was found mainly in Tunisia, Algeria and Egypt and the second in Iraq, Iran and Oman. We propose that earliest date palm cultivation occurred independently in at least 3 distinct locations. This discovery will further inform understanding of the history and origins of cultivated date palm.
\end{abstract}

Keywords: Date palm, Domestication, Cultivation, Organellar genome sequencing

\section{Background}

The importance of date palm to early civilizations is well documented and it is among the earliest cultivated fruit trees [1]. There are hundreds of commercially important date palm cultivars across the main growing regions of North Africa, the Middle East, Arabian Gulf and western parts of South Asia. Despite its historical importance, little is known about its earliest development and whether it was truly domesticated or simply cultivated. This is complicated by the fact that highly favored cultivars of

\footnotetext{
* Correspondence: jom2042@qatar-med.cornell.edu

${ }^{1}$ Genomics Laboratory, Weill Cornell Medicine-Qatar, Doha 24144, Qatar

2Department of Genetic Medicine, Weill Cornell Medicine-Qatar, Doha 24144, Qatar

Full list of author information is available at the end of the article
}

date palm are clonally propagated and likely have been since antiquity [2]. The absence of widely distributed wild date palm progenitors has further complicated the analysis though a recent study has identified potential wild date palms in Oman [3]. The date palm is dioecious with separate male and female trees and hybridization with other Phoenix species is possible and hybridization was recently shown to have likely occurred with $P$. theophrasti during the spread of date palm cultivation in North Africa [4].

Multiple studies, including our own, of Y chromosome or chloroplast markers and genome-wide SNP analysis has confirmed at least two major sub-populations in the date palm [5-9]. The subpopulations show strong

(c) The Author(s). 2019 Open Access This article is distributed under the terms of the Creative Commons Attribution 4.0 International License (http://creativecommons.org/licenses/by/4.0/), which permits unrestricted use, distribution, and reproduction in any medium, provided you give appropriate credit to the original author(s) and the source, provide a link to the Creative Commons license, and indicate if changes were made. The Creative Commons Public Domain Dedication waiver (http://creativecommons.org/publicdomain/zero/1.0/) applies to the data made available in this article, unless otherwise stated. 
distinction between North African (Western) and Arabian Gulf (Eastern) cultivars while admixture is observed in cultivars from Egypt, Sudan and the Middle East. High genetic diversity in the North Africa subpopulation argues against it simply a result of colonization from a middle-east population [8] though studies have shown a significant portion of the North Africa date palm genome likely originates from the Arabian Gulf date palm $[3,4,10]$. Despite these results, many have suggested that the date palm was originally domesticated in the region of modern day Iraq as the historical record of date palm is richest in that region [11]. Date palms do not figure in Egyptian hieroglyphics until the 12 century BC [12]. However, it has been argued that the date palm may have simply been a tree of horticultural importance in North Africa as opposed to its religious importance in the East where the historical record is documented earlier. Within this debate, others have suggested that the date palm was cultivated in multiple locations at different times and no single origin of cultivation will be located [13].

While analysis of nuclear genomic markers is highly informative for understanding genetic admixture patterns, little work has been done to study variation in organellar genomes of date palm cultivars from multiple geographical regions. Organellar genomes in angiosperms offer the benefit that, as in animals, they are transmitted from the maternal lineage with evidence for bipaternal transmission only in rare cases [14]. For these reasons, maternal transmission of organellar genomes could be of interest for studying the origins of date palm cultivation. Many groups have sequenced portions of the chloroplast genome and found numerous haplotypes within Tunisian [15, 16], Saudi Arabian [17] or Emirati cultivars [18]. This study presents organellar genome sequencing results from across these regions of cultivation.

\section{Results}

We collected 201 date palms from across the main regions of cultivation (Table 1) and included Brahea dulcis and 4 Phoenix species for comparison (Additional file 1). Maximum sequencing coverage approached up to thousands of fold coverage, however, SNP calling was conducted on a maximum of 250 randomly selected reads per position. Average utilized sequence coverage for the samples was $223 \mathrm{X}$ and no sample had less than an average of $86 \mathrm{X}$ coverage across the two organelle genomes. We believe this is the first reported organellar genome sequencing from dried date palm fruit.

SNP filters that required at least one high quality alternative allele in any of the samples studied resulted in 177 SNPs identified in the 158,462 bp Chloroplast genome and 841 in the 715,001 bp Mitochondria genomes for a total of 1018 SNPs (Additional file 3). Most of
Table 1 Counts of samples from each country and distribution among the Mitochondrial haplotypes

\begin{tabular}{llllll}
\hline Country & AG1 & AG2 & NA1 & NA2 & total \\
\hline Algeria & 12 & 0 & 13 & 3 & 28 \\
Egypt & 4 & 0 & 6 & 1 & 11 \\
Iran & 1 & 3 & 0 & 0 & 4 \\
Iraq & 3 & 0 & 0 & 0 & 3 \\
Jordan & 4 & 0 & 0 & 1 & 5 \\
Saudi Arabia & 17 & 3 & 1 & 0 & 21 \\
Libya & 1 & 0 & 4 & 0 & 5 \\
Morocco & 8 & 0 & 24 & 1 & 33 \\
Oman & 4 & 3 & 0 & 0 & 7 \\
Pakistan & 2 & 0 & 3 & 0 & 5 \\
Qatar & 5 & 2 & 0 & 0 & 7 \\
Sudan & 0 & 0 & 6 & 0 & 6 \\
Tunisia & 0 & 0 & 3 & 2 & 5 \\
UAE & 17 & 4 & 0 & 0 & 21 \\
USA & 12 & 2 & 15 & 10 & 40 \\
\hline
\end{tabular}

Haplotypes labels are as in Fig. 2. UAE - United Arab Emirates

these variants, however, are in Brahea or other Phoenix species and are not in any date palm samples studied here. Therefore, selecting only variants among date palm samples (Intra-date palm specific SNPs) identified 37 SNPs in the Chloroplast and 168 in the Mitochondria genomes for a total of 205 intra-date palm SNPs.

Among the 205 SNPs that were variable among date palm cultivars, we observed 4 major haplotypes (Fig. 1, Additional file 2). Interestingly, these haplotypes appeared to associate with the origin of the date palm cultivar (Additional file 1). When considering association of haplotypes with geographic origin it is important to note a cultivars historical origin. Commercially important cultivars have now spread across the world such as Medjool that is originally from North Africa yet grown in multiple countries including Jordan, Saudi Arabia and the United States. We noted that, as expected there were two major haplotypes with numerous samples that associated with collection in North Africa (NA1) or the Arabian Gulf (AG1) regions. However, we also detected additional haplotypes in North Africa (NA2) and the Arabian Gulf (AG2), though fewer samples had these haplotypes compared to NA1 and AG1 (Table 2). Of interest was that neither of the regions secondary haplotypes were limited to a single country. Indeed, for North Africa we detected the NA2 haplotype in cultivars originating from Tunisia, Algeria and Egypt. The AG2 haplotype was found in cultivars originating from Iraq, Iran and Oman. Moreover, the AG2 haplotype was more diverged from the AG1 haplotype than was the AG1 from the NA2 (Tables 3 and 4). Indeed, the higher 
Location

\begin{tabular}{|c|c|c|}
\hline \multirow[b]{3}{*}{ Haplotype } & \multicolumn{2}{|r|}{ Location } \\
\hline & Organelle & 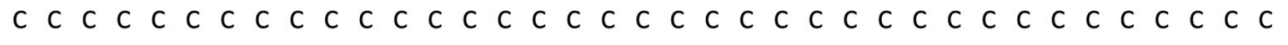 \\
\hline & Sample & 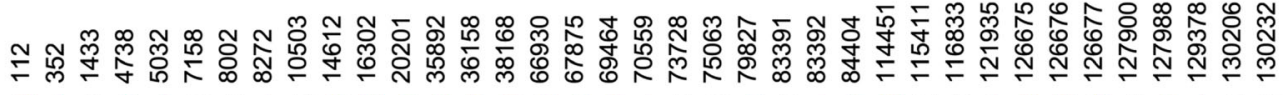 \\
\hline Outgroup & braheaSpp & $T A G C A G G A Y C T C C T T C \subset T A G G C G A C T G G A T T C G C A G G$ \\
\hline Phoenix & P3-ROE-US & $T A G C A G G A C A T C C T T Y C G A G G C G A C T G G A T T C G C A G G$ \\
\hline Phoenix & P6-CAN-US & $T A G C A G G A C A T C \subset T T C C G A G G C T C \subset T G G T T T C G \subset A G G$ \\
\hline Phoenix & Q19-THE-US & $T A G C A G G A C A T C \subset T T C \subset G A G G \subset G A C T G G A T T \subset G \subset A G G$ \\
\hline Phoenix & P24-SYL-US & $T A G T A G G A C A T T C C T C C T C G G C G A C C G G G A T T C T C G G G$ \\
\hline NorthAfica1 & 69-MDJL-US & $T A G T A A G A C C T T C C T C T T C G G T G A T C A A T G A A T T G G G$ \\
\hline NorthAfrica2 & DegNoor & $A G G C G G G G C A T C A T T G C G A A A C T C C T G G A T T C G \subset A T A$ \\
\hline ArabianGulf1 & 43-KHLS-QA & A G A C G G G G C A T C A T T G C G A A A C T C C T G G A T T C G C A T A \\
\hline ArabianGulf2 & 15-JBR-AE & $A G G C G G A G T A A C \subset T T G C G A A A C G A C T G G A G A A G \subset A G A$ \\
\hline
\end{tabular}

similarity between the NA2 and AG1 haplotypes suggest that the separation of the two groups occurred long after the other 3 (NA1, AG1 and AG2) haplotypes were cultivated. In summary SNP differences between the haplotypes when combining chloroplast and mitochondria (205 total SNPs considered) were as follows: AG1:AG2 96 SNPs, AG1:NA1 158 SNPs, AG1:NA2 10 SNPs, NA1: AG2 146 SNPs, NA1:NA2 156 SNPs, AG2:NA2 96 SNPs (see Tables 3 and 4 for haplotype similarity rather than divergence).

A fifth chloroplast haplotype was noted but only contained a single distinguishing position from the NA1 haplotype at bp 38,168. It was found in the "Thoory" cultivar, its known progeny from crosses (Additional file 1) and some cultivars developed in the USA that are likely derivatives of these crosses. The progeny of these crosses, despite, including paternal males from the Arabian Gulf, confirm that maternal transmission of the chloroplast and mitochondria is the norm in date palm.

To better understand the phylogenetic relationship of the organelle haplotypes, SNPs from the chloroplast or mitochondrial were used for phylogenetic tree construction. We selected single representatives from each of the four date palm haplotype groups and included multiple Phoenix species for comparison and Brahea dulcis as outgroup. Maximum-likelihood phylogenetic analysis revealed that the NA1 haplotype is significantly differentiated from the other haplotypes. An observation that

Table 2 Haplotype counts among samples in this project

\begin{tabular}{ll}
\hline Haplotype & Count \\
\hline North Africa 1 (NA1) & $76^{*}$ \\
North Africa 2 (NA2) & 18 \\
Arabian Gulf 1 (AG1) & 90 \\
Arabian Gulf 2 (AG2) & 17
\end{tabular}

*We found 7 samples within the NA1 haplotype that contained a single base difference and most derived from the "Thoory" cultivar agrees with previous phylogenetic analysis of nuclear markers for the North African cultivars [7, 8]. The NA1 date palm haplotype branched from $P$. sylvestris confirming the close relationship observed by others $[3,6$, 19] (Fig. 2).

Other groups studying chloroplast markers from Deglet Noor, a cultivar from Algeria and Tunisia have noted its similarity to Arabian Gulf cultivars [6, 19]. Indeed, the chloroplast of Deglet Noor (NA2) had a single difference to AG1, however, multiple distinguishing differences between the NA2 and AG1 haplotypes were found among mitochondrial markers (Additional file 2) and these were confirmed in cultivars from other countries (Table 1). We never observed mixing of mitochondrial and chloroplast haplotypes in a single cultivar as expected by the almost exclusive maternal transmission of the organellar genomes.

\section{Discussion}

By utilizing organellar genome sequencing we have identified two additional haplotypes representing subpopulations beyond the currently known North Africa/Arabian Gulf separation. While others have observed some further genetic subdivision of nuclear markers within the major populations [20], the sources of these subdivisions were not noted to be related to possible original maternal contributions to cultivar groups. The subpopulations identified here further distinguish cultivar origins within the main regions offering insight into the history of date palm cultivation.

Of interest was the identification of a significantly diverged second Arabian Gulf haplotype (AG2). AG2 is certainly closer to the AG1 haplotype (96/205 SNP differences combining chloroplast and mitochondria) or AG1 related NA2 haplotype (96/205 SNP differences) than the NA1 haplotype (146/205 SNP differences). However, the divergence between AG2 and AG1 is high when compared to the divergence of NA2 and AG1 (10/ 
Table 3 Matrix of similarity at Intra-Date Palm SNPs Sites. Only SNPs varying between date palm cultivars are documented, first number is total count of similar SNP calls per total SNPs called between two samples

\begin{tabular}{|c|c|c|c|c|c|c|c|c|c|}
\hline \multirow[t]{2}{*}{ Mitochondria } & AG2 & AG1 & NA1 & NA2 & $P$ & $P$ & $P$ & $P$ & $\mathrm{O}$ \\
\hline & 15-JBR-AE & 43-KHLS-QA & 69-MDJL-US & DegNoor & P24-SYL-US & P3-ROE-US & P6-CAN-US & Q19-THE-US & BraheaSpp \\
\hline \multicolumn{10}{|l|}{ Sample } \\
\hline 15-JBR-AE & $168 / 168$ & $83 / 168$ & $50 / 168$ & $82 / 168$ & $79 / 168$ & $95 / 160$ & $98 / 166$ & $100 / 167$ & $75 / 130$ \\
\hline 43-KHLS-QA & $83 / 168$ & $168 / 168$ & $43 / 168$ & $159 / 168$ & $74 / 168$ & $94 / 160$ & $89 / 166$ & $93 / 167$ & $70 / 130$ \\
\hline 69-MDJL-US & $50 / 168$ & $43 / 168$ & $168 / 168$ & $44 / 168$ & $129 / 168$ & $91 / 160$ & $108 / 166$ & $102 / 167$ & $68 / 130$ \\
\hline DegNoor & $82 / 168$ & $159 / 168$ & $44 / 168$ & $168 / 168$ & $75 / 168$ & $93 / 160$ & $88 / 166$ & $94 / 167$ & $68 / 130$ \\
\hline P24-SYL-US & $79 / 168$ & $74 / 168$ & $129 / 168$ & $75 / 168$ & $168 / 168$ & $112 / 160$ & $119 / 166$ & $116 / 167$ & $75 / 130$ \\
\hline P3-ROE-US & $95 / 160$ & $94 / 160$ & $91 / 160$ & $93 / 160$ & $112 / 160$ & $160 / 160$ & $128 / 159$ & $129 / 160$ & $93 / 125$ \\
\hline P6-CAN-US & $98 / 166$ & $89 / 166$ & 108/166 & $88 / 166$ & 119/166 & 128/159 & $166 / 166$ & $143 / 165$ & $92 / 130$ \\
\hline Q19-THE-US & $100 / 167$ & $93 / 167$ & $102 / 167$ & $94 / 167$ & $116 / 167$ & $129 / 160$ & $143 / 165$ & $167 / 167$ & $94 / 130$ \\
\hline BraheaSpp & $75 / 130$ & $70 / 130$ & $68 / 130$ & $68 / 130$ & $75 / 130$ & $93 / 125$ & $92 / 130$ & $94 / 130$ & 130/130 \\
\hline \multicolumn{10}{|l|}{ Chloroplast } \\
\hline \multicolumn{10}{|l|}{ Sample } \\
\hline 15-JBR-AE & $37 / 37$ & $26 / 37$ & $9 / 37$ & $27 / 37$ & $15 / 37$ & $23 / 37$ & $20 / 37$ & $23 / 37$ & $21 / 37$ \\
\hline 43-KHLS-QA & $26 / 37$ & $37 / 37$ & $4 / 37$ & $36 / 37$ & $16 / 37$ & $24 / 37$ & $25 / 37$ & $24 / 37$ & $21 / 37$ \\
\hline 69-MDJL-US & $9 / 37$ & $4 / 37$ & $37 / 37$ & $5 / 37$ & $25 / 37$ & $16 / 37$ & $16 / 37$ & $17 / 37$ & $18 / 37$ \\
\hline DegNoor & $27 / 37$ & $36 / 37$ & $5 / 37$ & $37 / 37$ & $17 / 37$ & $25 / 37$ & $26 / 37$ & $25 / 37$ & $22 / 37$ \\
\hline P24-SYL-US & $15 / 37$ & $16 / 37$ & $25 / 37$ & $17 / 37$ & $37 / 37$ & $28 / 37$ & $26 / 37$ & $29 / 37$ & $28 / 37$ \\
\hline P3-ROE-US & $23 / 37$ & $24 / 37$ & $16 / 37$ & $25 / 37$ & $28 / 37$ & $37 / 37$ & $33 / 37$ & $36 / 37$ & $33 / 37$ \\
\hline P6-CAN-US & 20/37 & $25 / 37$ & $16 / 37$ & $26 / 37$ & $26 / 37$ & $33 / 37$ & $37 / 37$ & $34 / 37$ & $31 / 37$ \\
\hline Q19-THE-US & $23 / 37$ & $24 / 37$ & $17 / 37$ & $25 / 37$ & $29 / 37$ & $36 / 37$ & $34 / 37$ & $37 / 37$ & $34 / 37$ \\
\hline braheaSpp & $21 / 37$ & $21 / 37$ & $18 / 37$ & $22 / 37$ & $28 / 37$ & $33 / 37$ & $31 / 37$ & $34 / 37$ & $37 / 37$ \\
\hline
\end{tabular}

205 SNP differences) (Tables 3 and 4). This suggests that the AG2 haplotype may represent a third early center of date palm cultivation with a significantly diverged maternal contributor (discussed below). The low number of SNPs between AG1 and NA2 suggests these two separated from each other much later than did the second Arabian Gulf haplotype (AG2). Likewise, the most common North African haplotype (NA1) is highly diverged from the Arabian Gulf haplotypes and likely represents a distinct, early center of date palm cultivation. Altogether, the genetic distinction among the 3 major haplotypes (AG1, AG2, NA1) suggests their geographic separation at the time of initial cultivation. That is, the haplotypes are highly diverged from each other so were

Table 4 Similarity matrix between samples of all SNPS. All documented SNPs are included, first number is total count of similar SNP calls per total SNPs called between two samples

\begin{tabular}{llllllllll}
\hline & AG2 & AG1 & NA1 & NA2 & $P$ & $P$ & $P$ & $P$ & O \\
\hline SAMPLE & $15-J B R-A E$ & $43-K H L S-Q A$ & $69-M D J L-U S$ & DegNoor & P24-SYL-US & P3-ROE-US & P6-CAN-US & Q19-THE-US & braheaSpp \\
15-JBR-AE & $1018 / 1018$ & $920 / 1018$ & $871 / 1018$ & $918 / 1018$ & $860 / 1018$ & $491 / 997$ & $719 / 1014$ & $784 / 1016$ & $291 / 851$ \\
43-KHLS-QA & $920 / 1018$ & $1018 / 1018$ & $859 / 1018$ & $1004 / 1018$ & $856 / 1018$ & $492 / 997$ & $716 / 1014$ & $779 / 1016$ & $286 / 851$ \\
69-MDJL-US & $871 / 1018$ & $859 / 1018$ & $1018 / 1018$ & $859 / 1018$ & $921 / 1018$ & $481 / 997$ & $726 / 1014$ & $781 / 1016$ & $281 / 851$ \\
DegNoor & $918 / 1018$ & $1004 / 1018$ & $859 / 1018$ & $1018 / 1018$ & $856 / 1018$ & $492 / 997$ & $713 / 1014$ & $778 / 1016$ & $285 / 851$ \\
P24-SYL-US & $860 / 1018$ & $856 / 1018$ & $921 / 1018$ & $856 / 1018$ & $1018 / 1018$ & $489 / 997$ & $739 / 1014$ & $783 / 1016$ & $296 / 851$ \\
P3-ROE-US & $491 / 997$ & $492 / 997$ & $481 / 997$ & $492 / 997$ & $489 / 997$ & $997 / 997$ & $527 / 994$ & $524 / 997$ & $419 / 836$ \\
P6-CAN-US & $719 / 1014$ & $716 / 1014$ & $726 / 1014$ & $713 / 1014$ & $739 / 1014$ & $527 / 994$ & $1014 / 1014$ & $787 / 1012$ & $319 / 851$ \\
Q19-THE-US & $784 / 1016$ & $779 / 1016$ & $781 / 1016$ & $778 / 1016$ & $783 / 1016$ & $524 / 997$ & $787 / 1012$ & $1016 / 1016$ & $323 / 850$ \\
braheaSpp & $291 / 851$ & $286 / 851$ & $281 / 851$ & $285 / 851$ & $296 / 851$ & $419 / 836$ & $319 / 851$ & $323 / 850$ & $851 / 851$ \\
\hline
\end{tabular}




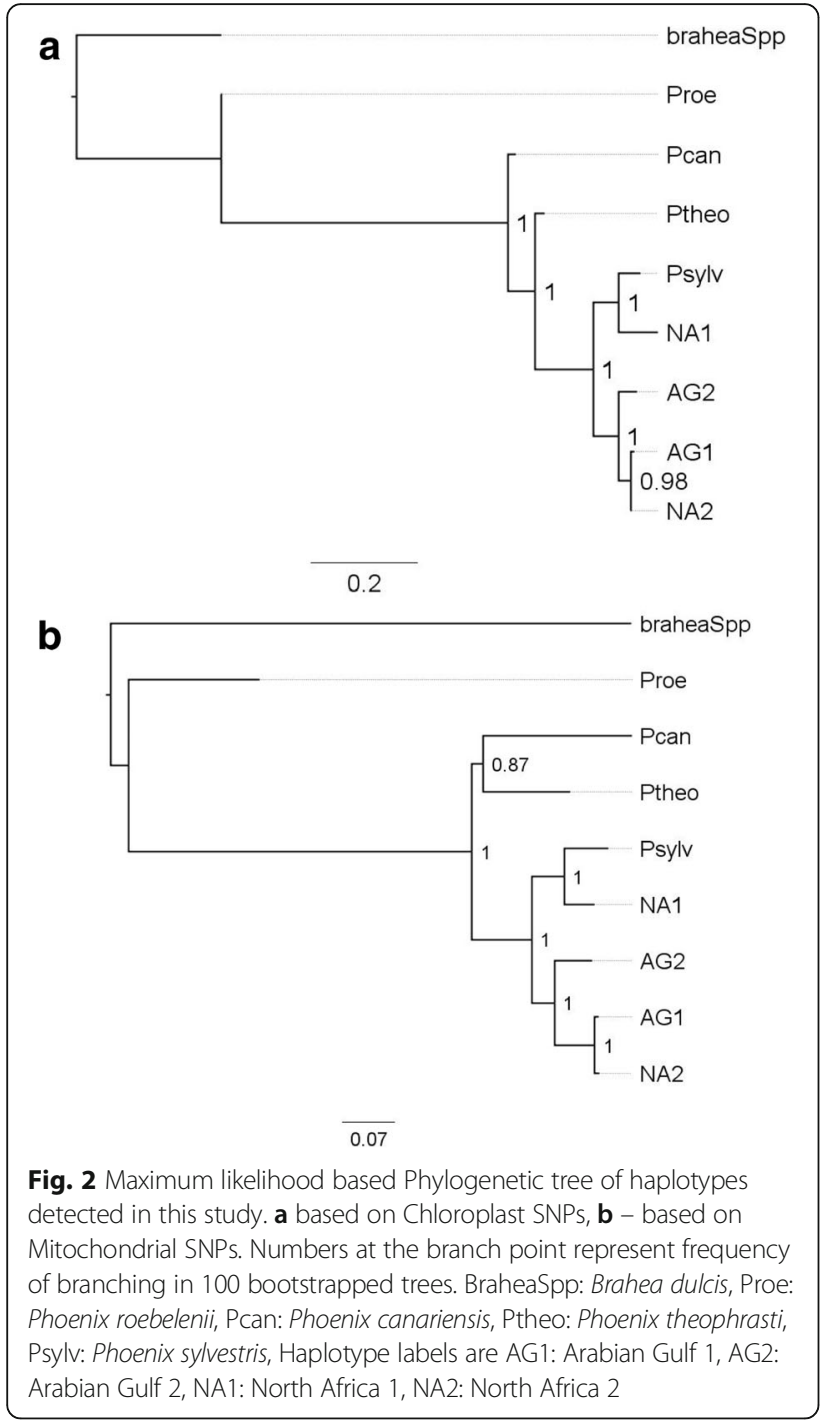

unlikely to have been first cultivated in the same region and at the same time.

The similarity of the major North African haplotype to $P$. sylvestris is important to note and agrees with the findings of Flowers and colleagues in their analyses of the date palm chloroplast and mitochondrial genomes [4]. Their findings show that while introgression from $P$. theophrasti occurred in the cultivation of the North African date palm, this was likely through male contribution as the chloroplast and mitochondrial genomes retain their close relationship to $P$. sylvestris. P. sylvestris is native to South Asia [21] and so closer to the regions cultivating the AG1 and AG2 haplotypes. It is possible that the maternal contributor to the major North African haplotype was $P$. sylvestris but how this would occur geographically requires further investigation. Nuclear markers from cultivars in this region show distinction from Arabian Gulf cultivars and are at the base of the date palm phylogenetic tree closer to other Phoenix species [7].
Whether the combination of nuclear and organellar information is indication of a highly distinct, ancient date palm in North Africa or simply introgression with $P$. sylvestris will require further research.

While the use of nuclear DNA markers assists in understanding admixture of populations, organellar genome markers can assist in understanding more simple maternal contributions. We see concordance with previous results from across the date palm cultivating regions that genotyped specific chloroplast markers and found 2 major haplotypes in date palm [6]. From the detail offered by genome sequencing, we can extend this to 4 haplotypes. Our results on the presence of a second chloroplast and mitochondrial haplotype in the Arabian Gulf agree with Flowers and colleagues [4], however in contrast, we see distinction between two North African chloroplast and mitochondrial haplotypes. These finding agree with both Zehdi-Azouzi and colleagues [6] and Pintaud and colleagues [19] that the chloroplast haplotype found in the group including Deglet Noor is genetically closer to the Arabian Gulf haplotype than to the major North African haplotype. Our results stand in contrast to others who have utilized just portions of the date palm chloroplast genome for sequence analysis. In Tunisian cultivars, some groups have found 8 haplotypes among 12 samples [16] or 14 haplotypes among 31 samples [15] utilizing the trnL intron or trnL-trnF spacer. Likewise 5 haplotypes were found in 30 Emirati cultivars [18] and 3 major groups in 8 Saudi Arabian cultivars [17]. These groups used PCR amplification followed by Sanger Sequencing and included insertions and deletions in their analysis but the discrepancy between the number of distinct haplotypes we observed is clear. We do not believe this is a result of false-negative SNP calls in the variable regions as we are able to call SNPs in these regions from Phoenix species or the outgroup palm. It is possibly a limitation of the stringency of SNP calling we utilized to ensure low false-positive SNP calls and that loosening these would identify additional minor subgroups within the major 4 haplotypes as occurred with the 'Thoory' derived cultivars. Nevertheless, it is clear that we only observe 4 major chloroplast and mitochondrial haplotype groups across the date palm growing world. We may identify additional ones in the future but these 4 haplotypes include a majority of the most famous and commercially important cultivars.

Based on the observation that the NA2 haplotype is more similar to the AG1 than any other haplotype suggests two possibilities. A recent ancestor of the NA2 haplotype may have been a maternal contributor to the AG1 cultivars or vice-versa. We propose that it was likely the NA2 haplotype that derived from the AG1 as they are both closer to the other Arabian Gulf haplotype (AG2) than the major North African 1 haplotype. This 
would then suggest that there were 3 major centers of date palm cultivation, two in the Arabian Gulf and one in North Africa. A fourth that derived from one of the Arabian Gulf cultivars then spread and includes the famous North African "Deglet Noor" and Egyptian "Zaghlool" cultivars.

The fact that we did not observe mixing of the haplotypes in all the cultivars studied here suggests that the haplotypes came into existence prior to the spread of cultivars and that transmission of the mitochondria and chloroplast is indeed tightly linked. Whether the centers of cultivation were initiated by transfer of male contributors from other regions, as was observed in the major North African cultivars or rather contribution occurred later in the cultivation process remains to be studied for the second Arabian Gulf haplotype. However, it is clear that the female contribution to each center was unique based on the haplotypes observed here.

\section{Conclusions}

The strong distinction between the haplotypes found here argues against a single center of date palm cultivation whose cultivars then spread to other regions with a bottleneck creating significant distinction. Rather, it suggests that there were likely 3 distinct centers of cultivation from which cultivars in those regions all derived from a single maternal contributor followed by a fourth that developed from the AG1 haplotype. These centers of cultivation were then responsible for hundreds of future cultivars that are now available with admixture of the nuclear genome occurring at the boundaries of these centers. The proximity of the most common North African haplotype to $P$. sylvestris requires further investigation and may explain some of the previously observed genetic structure in the overall date palm population. Altogether, these results inform our understanding of the earliest origins of date palm cultivation.

\section{Methods}

Sample collection and genome sequencing

Date fruit samples were from the Qatar date fruit biobank [22], a collection of date fruit samples from across the date palm growing region spanning from Morocco in the West to Pakistan in the East (Additional file 1). Briefly, the fruit samples in the Qatar date fruit biobank were obtained from commercial outlets in the country of collection or local farms with identification by the product packaging or farmer. We attempted to select the most important commercial cultivars as well as lesser known varieties so as to represent the genetic diversity in regions. We also sequenced a subset of Phoenix species identified by and collected from the USDA palm collection and the outgroup palm Brahea dulcis identified by and collected from the Huntington library botanical garden palm collection (San Marino, CA, USA). DNA from fruit for date palm, or leaves for other species, was extracted as described [7]. Sequencing libraries were constructed from total DNA and sequenced on Illumina HiSeq 2500/4000 instruments with paired $150 \mathrm{bp}$ reads according to the manufacturers recommended protocol.

\section{Sequence analysis}

Sequences were aligned to the complete date palm chloroplast (NCBI ID NC_013991.2, GI:300399125) and mitochondrial (NCBI ID NC_016740.1, GI:372450205) reference genomes of the Eastern cultivar Khalas [23, 24] using BOWTIE2 [25] and Single Nucleotide Polymorphisms (SNPs) called with SAMTOOLS [26]. We removed sites that were heterozygous in multiple date palms as these are likely duplicated, repetitive or nuclear transferred mitochondrial (NucMt) sequences rather than simple sequence errors or heteroplasmy. In one analysis, a single alternative allele was required in at least one of the date palms analyzed for a SNP to be called across the population (Intra-date palm specific SNPs). A second analysis simply required a variant in any sample including other Phoenix and outgroup palms. We excluded insertions or deletions and required an overall population SNP call quality of greater than 900 .

\section{Phylogenetic analysis}

Polymorphic sites in the form of a VCF file were transformed into PHYLIP formatted sequence using VCF2PHYLIP [27]. We conducted phylogenetic analysis with PhyML [28] using both bootstrap and ML approaches. Phylogenetic trees were plotted with FIGTREE (http://tree.bio.ed.ac.uk/ software/figtree/).

\section{Additional files}

Additional file 1: Cultivar Information. Table containing information on date palm cultivars analyzed in this study. (XLSX $17 \mathrm{~kb}$ )

Additional file 2: Mitochondrial and Chloroplast Haplotype SNP Positions. Table containing genotypes for all intra-date palm SNP positions in the Mitochondrial and Chloroplast haplotypes identified in this study. (XLSX 18 kb)

Additional file 3: Date Palm Genotypes. File containing all genotypes utilized in this analysis in vcf format. (VCF $3902 \mathrm{~kb}$ )

\section{Abbreviations}

AG1: Arabian Gulf Haplotype 1 (Chloroplast and Mitochondria); AG2: Arabian Gulf Haplotype 1 (Chloroplast and Mitochondria); ML: Maximum likelihood; NA1: North Africa Haplotype 1 (Chloroplast and Mitochondria); NA2: North Africa Haplotype 2 (Chloroplast and Mitochondria); NCBI: National Center for Biotechnology Information; NucMt: Nuclear transferred mitochondrial sequences; SNP: Single Nucleotide Polymorphism; USDA: United States Department of Agriculture

\section{Acknowledgments}

We thank Sean Lahmeyer at the Huntington Gardens for his kind assistance with collection of Brahea dulcis. We thank Diego Rivera and Encarnacion Carreño from the University of Murcia and Concepcion Obón from the 
University of Miguel Hernandez (National Phoenix Palm Germplasm Repository of Spain) for their assistance in collection of Phoenix theophrasti.

\section{Authors' contributions}

YAM directed library construction and sequencing and conducted bioinformatics analysis, LSM conducted genome sequencing, library construction, MFT conducted sample collection and analysis, SY conducted data management and bioinformatics analysis, RK maintained palm collections, conducted sample collection, provided phenotyping and systematics analysis, KS conducted bioinformatics analysis and helped write the manuscript, JAM envisioned the project, conducted bioinformatics analysis and wrote the manuscript. All authors have read and approve this manuscript.

\section{Funding}

This study was made possible by grant NPRP-EP X-014-4-001 from the Qatar National Research Fund (a member of Qatar Foundation). The funding agency did not participate in the study design, sample collection, analysis, data interpretation or writing of this research.

\section{Availability of data and materials}

All data generated or analysed during this study are included in this published article and its supplementary information files.

\section{Ethics approval and consent to participate}

Not applicable as human or animal subjects were not included.

\section{Consent for publication}

Not applicable.

\section{Competing interests}

The authors declare that they have no competing interests.

\section{Author details}

${ }^{1}$ Genomics Laboratory, Weill Cornell Medicine-Qatar, Doha 24144, Qatar ${ }^{2}$ Department of Genetic Medicine, Weill Cornell Medicine-Qatar, Doha 24144 Qatar. ${ }^{3}$ Dipartimento di Scienze Agrarie e Forestali, Università degli Studi di Palermo, 90128 Palermo, Italy. ${ }^{4}$ USDA-ARS National Clonal Germplasm Repository for Citrus \& Dates, Riverside, CA, USA. ${ }^{5}$ Department of Physiology, Weill Cornell Medicine-Qatar, Doha 24144, Qatar. ${ }^{6}$ Present Address: Department of Biological Sciences, University of Cincinnati, Cincinnati, $\mathrm{OH}$, USA

\section{Received: 10 September 2018 Accepted: 23 May 2019}

Published online: 17 June 2019

\section{References}

1. Zohary D, Spiegel-Roy P. Beginnings of fruit growing in the Old World Science (80-). 1975;187:319-27. http://view.ncbi.nlm.nih.gov/pubmed/ 17814259 .

2. Pliny the $\mathrm{E}$, Bostock J, Riley HT. The natural history of Pliny. London: H. G. Bohn; 1855. https://www.biodiversitylibrary.org/item/36497.

3. Gros-Balthazard M, Galimberti M, Kousathanas A, Newton C, Ivorra S, Paradis $L$, et al. The discovery of wild date palms in Oman reveals a complex domestication history involving centers in the Middle East and Africa. Curr Biol. 2017;27:2211-2218.e8. https://doi.org/10.1016/j.cub.2017.06.045.

4. Flowers JM, Hazzouri KM, Gros-Balthazard M, Mo Z, Koutroumpa K, Perrakis A, et al. Cross-species hybridization and the origin of north African date palms. Proc Natl Acad Sci. 2019;116:1651 LP-658. https://doi.org/10.1073/ pnas.1817453116.

5. Cherif E, Zehdi S, Castillo K, Chabrillange N, Abdoulkader S, Pintaud J-C, et al. Male-specific DNA markers provide genetic evidence of an XY chromosome system, a recombination arrest and allow the tracing of paternal lineages in date palm. New Phytol. 2013;197:409-15. https://doi. org/10.1111/nph.12069.

6. Zehdi-Azouzi S, Cherif E, Moussouni S, Gros-Balthazard M, Abbas Naqvi S, Ludeña B, et al. Genetic structure of the date palm (Phoenix dactylifera) in the Old World reveals a strong differentiation between eastern and western populations. Ann Bot. 2015;116:101-12. https://doi.org/10.1093/aob/mcv068.

7. Mathew LS, M a S, George B, Mathew S, Spannagl M, Haberer G, et al. A genome-wide survey of date palm cultivars supports two major subpopulations in Phoenix dactylifera. G3 (Bethesda). 2015;5:1429-38.
8. Hazzouri KM, Flowers JM, Visser HJ, Khierallah HSM, Rosas U, Pham GM, et al. Whole genome re-sequencing of date palms yields insights into diversification of a fruit tree crop. Nat Commun. 2015;6:8824. https://doi.org/ 10.1038/ncomms9824.

9. Torres MF, Mathew LS, Ahmed I, Al-Azwani IK, Krueger R, Rivera-Nunez D, et al. Genus-wide sequencing supports a two-locus model for sexdetermination in Phoenix. Nat Commun. 2018;9:3969.

10. Gros-Balthazard M, Hazzouri KM, Flowers JM. Genomic insights into date palm origins. Genes. 2018;9. https://doi.org/10.3390/genes9100502.

11. Tengberg M. Beginnings and early history of date palm garden cultivation in the Middle East. J Arid Environ. 2012;86:139-47. https://doi.org/10.1016/j. jaridenv.2011.11.022

12. Popenoe P. The date-palm in antiquity. Sci Mon. 1924;19:313-25. https://doi. org/10.2307/7328

13. Nixon RW. The date palm: "tree of life" in the subtropical deserts. Econ Bot. 1951;5:274-301 http://www.jstor.org/stable/4252037.

14. Corriveau JL, Coleman AW. Rapid screening method to detect potential Biparental inheritance of plastid DNA and results for over 200 angiosperm species. Am J Bot. 1988;75:1443. https://doi.org/10.2307/2444695.

15. Soumaya R-C, Sarra C, Salwa Z-A, Khaled C, Khaled S. Molecular polymorphism and phylogenetic relationships within Tunisian date palm (Phoenix dactylifera L.): evidence of non-coding trnL-trnF regions of chloroplast DNAs. Sci Hortic (Amsterdam). 2014;170:32-8. https://doi.org/10. 1016/J.SCIENTA.2014.02.027.

16. Sakka H, Baraket G, Dakhlaoui Dkhil S, Zehdi Azzouzi S, Salhi-Hannachi A. Chloroplast DNA analysis in Tunisian date-palm cultivars (Phoenix dactylifera L.): sequence variations and molecular evolution of trnL (UAA) intron and trnL (UAA) trnF (GAA) intergenic spacer. Sci Hortic (Amsterdam). 2013;164: 256-69. https://doi.org/10.1016/J.SCIENTA.2013.09.038.

17. Al-Qurainy F, Khan S, Al-Hemaid FM, Ali MA, Tarroum M, Ashraf M. Assessing molecular signature for some potential date (Phoenix dactylifera L.) cultivars from Saudi Arabia, based on chloroplast DNA sequences rpoB and psbAtrnH. Int J Mol Sci. 2011;12:6871-80. https://doi.org/10.3390/ijms12106871.

18. Enan MR, Ahmed A. Cultivar-level phylogeny using chloroplast DNA barcode psbK-psbl spacers for identification of Emirati date palm (Phoenix dactylifera L) varieties. Genet Mol Res. 2016;15. https://doi.org/10.4238/gmr.15038470.

19. Pintaud J-C, Ludeña B, Aberlenc-Bertossi F, Zehdi S, Gros-Balthazard M, Ivorra S, et al. Biogeography of the date palm (Phoenix dactylifera L., Arecaceae): insights on the origin and on the structure of modern diversity. Acta Hort. 2013;994:19-38.

20. Chaluvadi SR, Khanam S, Aly MAM, Bennetzen JL. Genetic diversity and population structure of native and introduced date palm (Phoenix dactylifera) germplasm in the United Arab Emirates. Trop Plant Biol. 2014;7: 30-41. https://doi.org/10.1007/s12042-014-9135-7.

21. Barrow SC. A monograph of Phoenix L. (Palmae: Coryphoideae). Kew Bull. 1998;53:513-75. https://doi.org/10.2307/4110478.

22. Stephan N, Halama A, Mathew S, Hayat S, Bhagwat A, Mathew LS, et al. A comprehensive metabolomic data set of date palm fruit. Data Br. 2018;18: 1313-21. https://doi.org/10.1016/J.DIB.2018.04.012.

23. Fang $Y, W u H$, Zhang $T$, Yang $M$, Yin $Y$, Pan $L$, et al. A complete sequence and transcriptomic analyses of date palm (Phoenix dactylifera L.) mitochondrial genome. PLoS One. 2012;7:e37164. https://doi.org/10.1371/ journal.pone.0037164.

24. Yang M, Zhang X, Liu G, Yin Y, Chen K, Yun Q, et al. The complete chloroplast genome sequence of date palm (Phoenix dactylifera L.). PLoS One. 2010;5:e12762. https://doi.org/10.1371/journal.pone.0012762.

25. Langmead B, Trapnell C, Pop M, Salzberg SL. Ultrafast and memory-efficient alignment of short DNA sequences to the human genome. Genome Biol. 2009:10:R25. https://doi.org/10.1186/gb-2009-10-3-r25.

26. Li H, Handsaker B, Wysoker A, Fennell T, Ruan J, Homer N, et al. The sequence alignment/map format and SAMtools. Bioinformatics. 2009:25: 2078-9. https://doi.org/10.1093/bioinformatics/btp352.

27. Ortiz EM. vcf2phylip v1.5: convert a VCF matrix into several matrix formats for phylogenetic analysis; 2018. https://doi.org/10.5281/ZENODO.1257058.

28. Guindon S, Lethiec F, Duroux P, Gascuel O. PHYML online--a web server for fast maximum likelihood-based phylogenetic inference. Nucleic Acids Res. 2005;33(Web Server):W557-9. https://doi.org/10.1093/nar/gki352.

\section{Publisher's Note}

Springer Nature remains neutral with regard to jurisdictional claims in published maps and institutional affiliations. 